\title{
Thigh Pain in an 18-year-old Man
}

\author{
Frank Traub MD, PhD, Marilyn Heng MD, \\ Brendan C. Dickson MD, MSc, Peter C. Ferguson MD, MSc
}

Received: 2 May 2014/Accepted: 31 July 2014/Published online: 15 August 2014

(C) The Association of Bone and Joint Surgeons(B) 2014

\section{History and Physical Examination}

An 18-year-man presented to a tertiary orthopaedic oncology referral center with a $1 \frac{1 / 2}{2}$-year history of right thigh pain. He had no history of trauma or constitutional symptoms such as fevers, chills, or night pain. He described the intensity of pain as unchanged since its onset; it occurred mainly with walking or physical activity and was improved with the use of NSAIDs. Previous treatment with physical therapy resulted in no improvement. His medical and surgical histories were noncontributory. There was no family history of medical illnesses; in particular there was no history of cancer or other musculoskeletal diseases. On physical examination, he was a

Each author certifies that he or she, or a member of his or her immediate family, has no funding or commercial associations (eg, consultancies, stock ownership, equity interest, patent/licensing arrangements, etc) that might pose a conflict of interest in connection with the submitted article.

All ICMJE Conflict of Interest Forms for authors and Clinical Orthopaedics and Related Research editors and board members are on file with the publication and can be viewed on request.

Each author certifies that his or her institution approved the reporting of this case report, that all investigations were conducted in conformity with ethical principles of research, and that informed consent was obtained.

F. Traub ( $₫)$, M. Heng, P. C. Ferguson

University Musculoskeletal Oncology Unit, Mount Sinai

Hospital, Toronto, ON M5G 1X5, Canada

e-mail: frank.traub@mail.utoronto.ca

B. C. Dickson

Department of Pathology and Laboratory Medicine, Mount Sinai

Hospital, Toronto, ON, Canada well-appearing man in no acute distress. He ambulated with an antalgic gait favoring the right leg. Musculoskeletal examination revealed his right lower extremity to have normal neurologic and vascular findings. No palpable mass or localized area of tenderness was present, and ROM of the hip and knee were normal. Radiographs (Fig. 1) and MRI (Fig. 2) were obtained. The remainder of his examination and complete blood count and inflammatory markers were normal.

\section{Imaging Interpretation}

Radiographs of the right femur showed a 4.6-cm long surface lesion involving the medial cortex of the proximal femur (Fig. 1). The lesion was located approximately $3.5 \mathrm{~cm}$ distal to the lesser trochanter. It was a well-circumscribed radiolucent lesion with a narrow zone of transition and no internal matrix. There was well-organized, thick, periosteal new bone formation proximal and distal to the lesion.

On MR images (Fig. 2) the lesion was confined solely to the cortical bone; there was no extension into the medullary canal. The lesion had a signal isointense to muscle on the T1-weighted sequence and hyperintense on the T2-weighted sequence. Just distal to the surface lesion, there is abnormal bright signal on the T2-weighted coronal MR image (Fig. 2), which may represent either edema or tumor.

The radiographic appearance of the lesion was consistent with a nonaggressive process.

Based on the history, physical examination, laboratory studies, and imaging studies, what is the differential diagnosis at this point? 


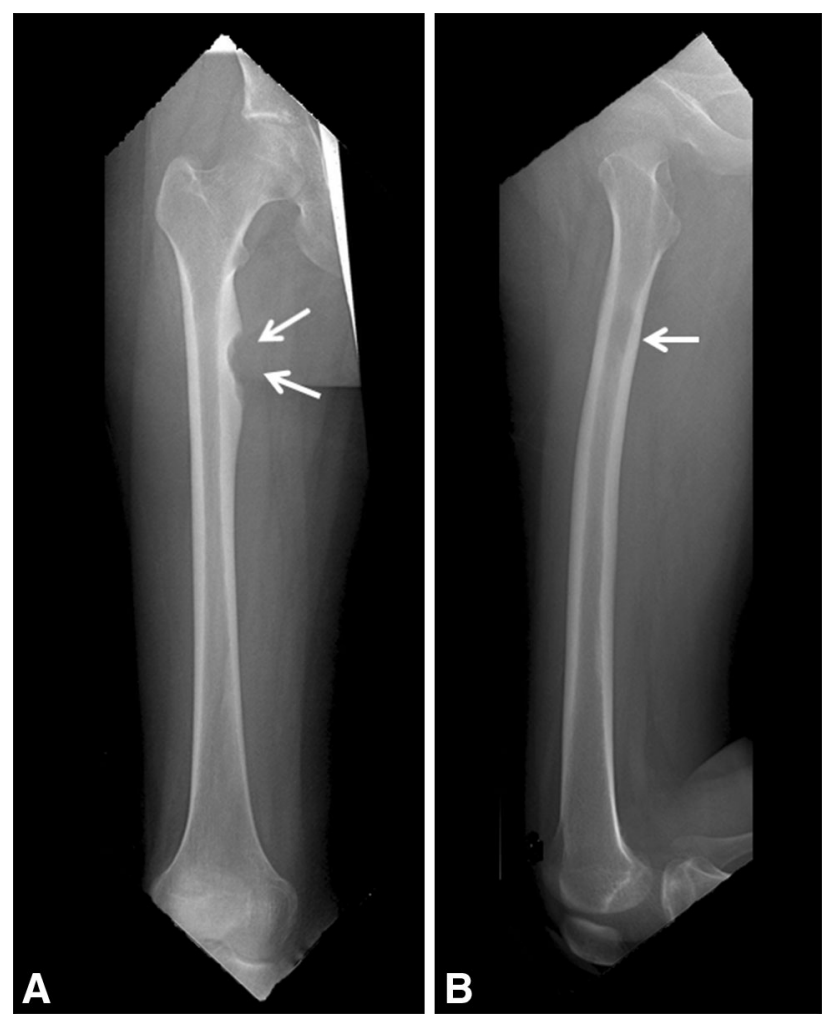

Fig. 1A-B (A) AP and (B) lateral view radiographs of the patient's right femur on presentation show the surface-based radiolucent lesion (arrows) that is well-circumscribed with a narrow zone of transition. The surrounding periosteal reaction is well-organized, smooth, and thick.

\section{Differential Diagnosis}

\author{
Periosteal chondroma \\ Periosteal chondrosarcoma \\ Nonossifying fibroma/fibrous cortical defect \\ Lymphoma of bone \\ Subacute osteomyelitis \\ Langerhans cell histiocytosis
}

Because of the nonaggressive radiographic characteristics and the high suspicion that this was a benign entity, the patient was taken to the operating room and an open biopsy with frozen section was performed. The frozen section confirmed a benign diagnosis so we proceeded with complete curettage of the lesion (Fig. 3).

Based on the history, physical examination, laboratory studies, imaging studies, and histologic picture, what is the diagnosis and how should the patient be treated?

\section{Histology Interpretation}

Grossly, the tissue was soft and friable, and red-tan to yellow. Histologically, the tumor was composed of nodules of epithelioid spindle cells (Fig. 3A). The cytoplasm was pale and eosinophilic. The nuclei were ovoid with prominent clefts and grooves; mitotic activity was not conspicuous ( 0 per 10 high power fields). Numerous eosinophils were interspersed throughout the lesion. Peripherally lymphoid follicles, aggregates of foamy macrophages and rare interspersed osteoclast-like giant cells were seen. Immunohistochemistry confirmed the presence of expression for S100, CD1a, and CD207 (langerin) (Fig. 3B-D).

\section{Diagnosis}

Langerhans cell histiocytosis

\section{Discussion and Treatment}

The clinical symptoms of Langerhans cell histiocytosis are quite variable and nonspecific [18]. Histopathologic confirmation is necessary for diagnosis because the clinical and imaging characteristics of Langerhans cell histiocytosis overlap with several other disease processes, including malignancy, infection, and other benign tumors of bone [11]. The clinical findings of our patient are consistent with the diagnosis of Langerhans cell histiocytosis. The radiographs showed a radiolucent lesion with a narrow zone of transition, indicative of a benign etiology.

Because this was a painful, diaphyseal cortical-based lesion in an 18-year old man, periosteal chondroma was thought to be the most likely diagnosis [3]. Periosteal chondromas (juxtacortical chondromas) are rare, benign, cartilage-forming tumors. They arise from the periosteum of the bone in children or young adults and erode into the cortex. Clinical features may include pain at the site of the lesion and a palpable, nontender, hard mass that is fixed to bone. On plain radiographs, periosteal chondromas appear as small, scalloped, radiolucent lesions on the outer surface of the cortex in the metaphysis or diaphysis as was seen on our patient's radiographs. Calcification is present in approximately $1 / 3$ of cases [3]. Typically, periosteal reaction is minimal in periosteal chondroma; however, in our patient the periosteal new bone formation was thickly formed. Histologically, these neoplasms consist of hypocellular lobules of mature hyaline cartilage. The chondrocyte nuclei are small and may exhibit mild pleomorphism and conspicuous binucleation [2]. The histology confirmed that periosteal chondroma was not the diagnosis of our patient. The radiographic appearances of periosteal chondroma and periosteal chondrosarcoma are similar. Size has been reported to be the most significant differentiator, with periosteal chondrosarcomas generally being 

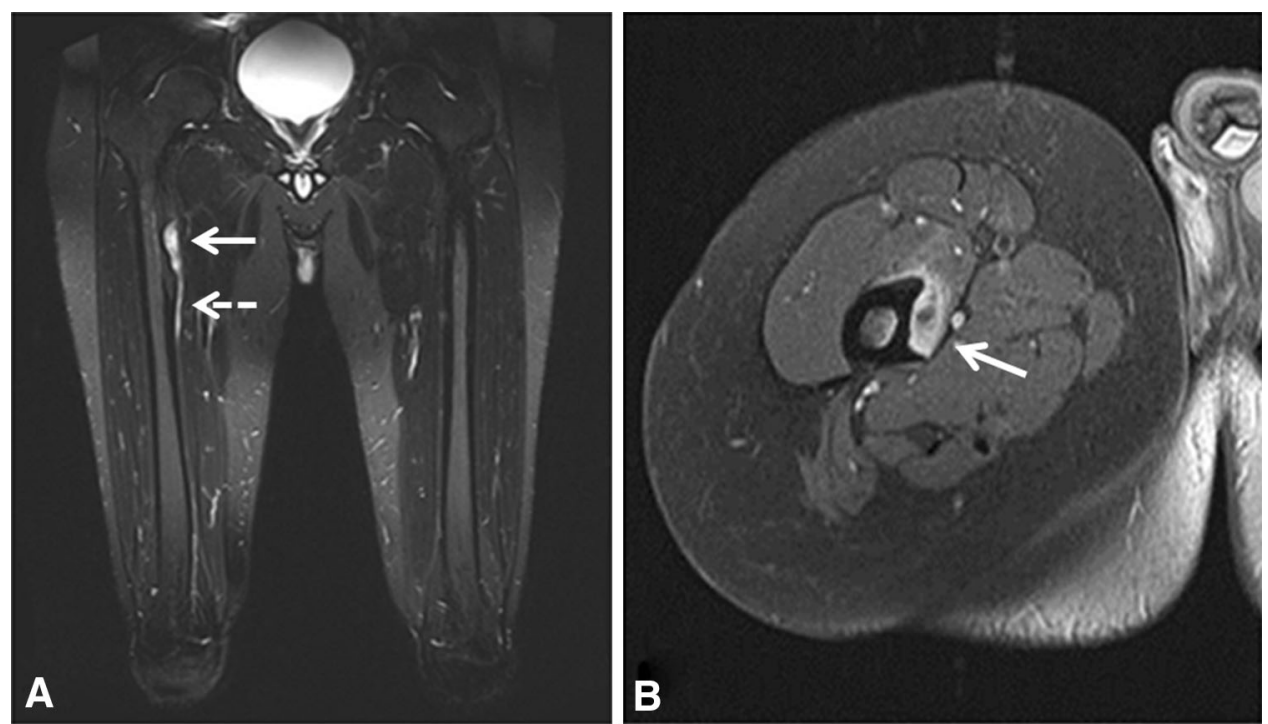

Fig. 2A-B The (A) coronal T2-weighted and (B) axial T1-weighted with contrast MR images show the lesion was confined solely in the cortical bone (solid white arrows); however, distal abnormal signal (dashed white arrow) may represent edema or tumor extension.

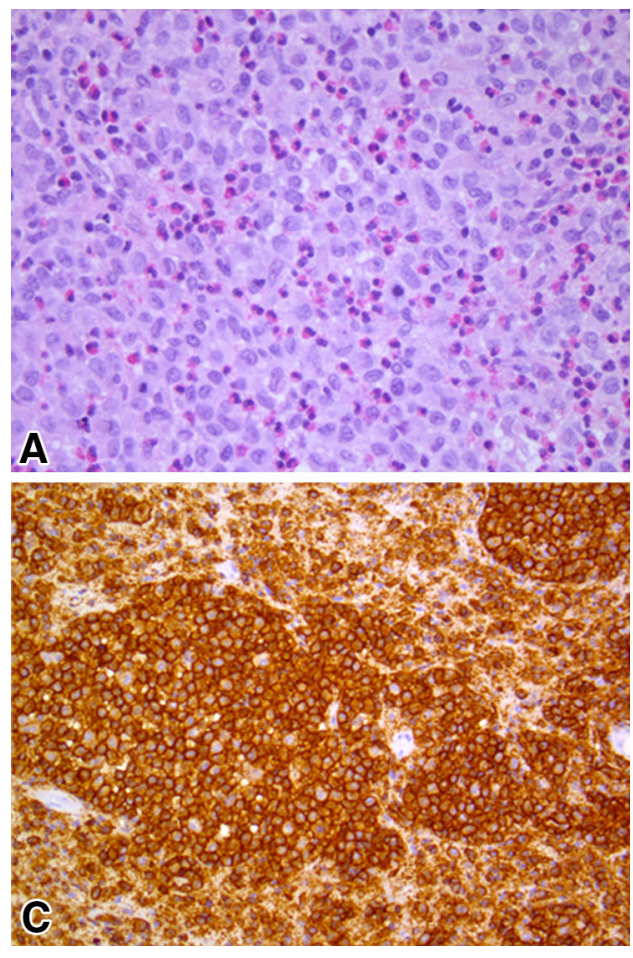

Fig. 3A-D (A) A histologic section shows sheets of Langerhans cells with interspersed eosinophils (Stain, hematoxylin \& eosin; original magnification, $\times 400$ ). The Langerhans cells are highlighted by

larger [20]. With the size of the lesion in our patient at $4.6 \mathrm{~cm}$, periosteal chondrosarcoma also was included in the differential diagnosis.

A nonossifying fibroma is a benign fibrous lesion that is known as a metaphyseal cortical defect or fibrous cortical defect [21]. It is thought to be a developmental defect in
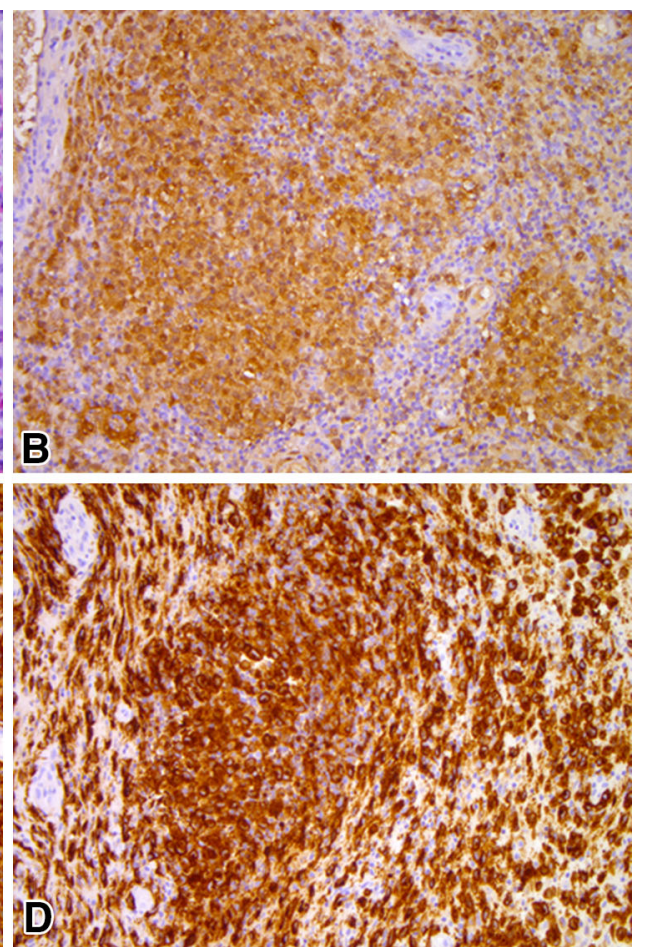

immunohistochemistry for (B) S100, (C) CD1a, and (D) CD207 (langerin) (Stain, hematoxylin counterstain; original magnification, $\times 200)$.

which areas that normally ossify are filled with fibrous connective tissue. Usually it is an incidental radiographic finding in adolescents and teenagers because it typically does not cause any symptoms. It is located most commonly in the metaphysis of the distal femur, followed by the distal tibia, and the proximal tibia. Large lesions may be 
associated with pathologic fracture [5]. On plain radiographs, nonossifying fibromas appear as well-defined, eccentric, expansile, lytic lesions, often described as having a "soap bubble" appearance, located in the metaphysis with scalloped sclerotic borders. MR images usually show the lesions to be of low signal intensity on T1-weighted and $\mathrm{T} 2$-weighted imaging. In our patient, the lesion was clearly located in the diaphysis, but had scalloped sclerotic borders. The MRI findings were not typical of a nonossifying fibroma. Additionally, the histologic analysis did not show the histopathologic findings typical of these entities, namely a cellular proliferation of fibroblasts with a storiform growth pattern and prominent interspersed osteoclasttype giant cells.

Primary lymphoma of bone is a rare group of tumors that account for fewer than $2 \%$ of all lymphomas in adults and approximately $3 \%$ to $9 \%$ of non-Hodgkin lymphoma cases in children [15]. Swelling, soft tissue mass, pathologic fracture, pain not relieved by rest, and systemic B-symptoms (ie, fever, weight loss, night sweats) also may be present at the time of diagnosis. Symptoms may persist for many months before the patient seeks medical attention [14]. Laboratory results can include anemia, thrombocytopenia, leukopenia, hypercalcemia, or elevated serum lactate dehydrogenase and erythrocyte sedimentation rate [15]. Radiographic findings in primary lymphoma of bone are nonspecific and have a highly variable appearance on plain radiographs. The appearance on MR images is homogeneously isointense with muscle on T1-weighted images and intermediate signal on T2-weighted images [9]. The results of the histopathologic examination are dependent on the subtype of lymphoma present. The most common primary non-Hodgkin lymphoma presenting in bone is a diffuse large B-cell lymphoma, which is characterized by destructive sheets of large and atypical lymphocytes. Less common subtypes include follicular lymphoma and anaplastic large cell lymphoma, in addition to other less common B- and T-cell lymphoma subtypes. Appropriate classification frequently depends on rigorous immunohistochemical analysis. Our patient lacked B-symptoms but clinical and radiographic findings would fit with the diagnosis, however the histomorphologic analysis excluded lymphoma. Diffuse large B-cell lymphoma typically lacks eosinophils, and consists of sheets of large and atypical lymphocytes. Our patient's immunohistochemistry showed immunoreactivity for S100, CD1a, and langerin, whereas diffuse large B-cell lymphoma generally is characterized by immunoreactivity for markers such as CD20, CD45, CD79a, and PAX5.

Subacute osteomyelitis, which is associated with a longer duration of symptoms, is observed most often in adolescents who present with pain and tenderness in the long bones such as the tibia and femur [7]. The pain is less severe, there is minimal fever, and there are few constitutional symptoms. Our patient lacked constitutional and nonmechanical symptoms, elevated inflammatory markers, and peritumoral edema on MR images. The typical histologic features of chronic inflammation, including lymphocytes, plasma cells, and neutrophils, were not found.

Langerhans cell histiocytosis is a rare histiocytic disorder most commonly characterized by single or multiple osteolytic bone lesions [8]. The true incidence of this condition is unknown as many instances of this disease are asymptomatic and thus not treated and confirmed with a histologic diagnosis. A male predominance has been described in some case series $[1,12]$. The incidence seems to be higher in people of northern European descent than in people of African or Asian descent [13]. The clinical presentation of Langerhans cell histiocytosis may vary from a solitary lesion of bone to a fulminant systemic involvement (Hand-Schüller-Christian disease and Letterer-Siwe disease) [19]. The World Health Organization 2013 guidelines [6] prefer the use of the term Langerhans cell histiocytosis; however, the term eosinophilic granuloma often is used when the disease is limited to bone or lung. Bone involvement occurs in the majority of patients and can involve any bone of the body; monostotic disease is more common than polyostotic involvement. While the most common skeletal manifestations of Langerhans cell histiocytosis appear in the skull and spine, approximately $30 \%$ of lesions occur in the long bones $[8,19]$. Although some lesions are asymptomatic, the patient may report pain in a localized area of bone; examination usually reveals a raised, soft, tender spot. Radiologic studies typically show an intramedullary, diaphyseal lytic lesion with endosteal scalloping without a break in the cortex or soft tissue mass. Cortical thinning, intracortical tunneling, and medullary widening often are seen on radiographs [19]. Sometimes an accompanying soft tissue mass is present. Occurrences of eosinophilic granuloma as a purely cortical lesion rarely are reported in the literature and are seen mainly in conjunction with multifocal disease [10]. To our knowledge, only one other case of a solitary surface eosinophilic granuloma has been reported [16].

For an eosinophilic granuloma, treatment of a symptomatic solitary lytic lesion affecting a long bone is best accomplished by curettage of the affected site with or without implantation of allograft bone chips or injections of corticosteroids into the lesion. Spontaneous regression of lesions has been reported in multiple studies [4, 17, 22]. The lesions rarely recur after treatment, although it has been suggested that an eosinophilic granuloma in adults may represent a more aggressive form of the disease and be associated with a higher relapse rate [18]. 
In our patient, the lesion was treated by curettage. The patient did not receive any additional therapy and his pain resolved within 2 weeks of the procedure. He returned to normal physical activity after 4 weeks. Staging was completed with total body bone scan and chest radiographs to rule out other sites of involvement. A total body bone scan was used for staging since Langerhans cell histiocytosis usually has enhanced uptake on bone scan, thus it is more comprehensive than skeletal survey and it is more costeffective than positron emission tomography. Chest radiographs showed no pulmonary involvement and the bone scan confirmed no other sites of bony disease. He will be followed in the future with clinical history and physical examination and radiographs of the right femur. Presently, at 9 months followup, the radiographs show the lesion to be filled in with sclerotic bone and the patient has resumed all of his regular activities.

Our experience suggests that although Langerhans cell histiocytosis of the cortex is rare, it should be included in the differential diagnosis of bone tumors in children and adolescent patients. Early identification allows prompt treatment, which leads to resolution of the tumor and prevention of pathologic fractures.

\section{References}

1. Aricò M, Girschikofsky M, Généreau T, Klersy C, McClain K, Grois N, Emile JF, Lukina E, De Juli E, Danesino C. Langerhans cell histiocytosis in adults: report from the International Registry of the Histiocyte Society. Eur J Cancer. 2003;39:2341-2348.

2. Boriani S, Bacchini P, Bertoni F, Campanacci M. Periosteal chondroma: a review of twenty cases. J Bone Joint Surg Am. 1983;65:205-212.

3. Brien EW, Mirra JM, Luck JV Jr. Benign and malignant cartilage tumors of bone and joint: their anatomic and theoretical basis with an emphasis on radiology, pathology and clinical biology: II. Juxtacortical cartilage tumors. Skeletal Radiol. 1999;28:1-20.

4. Cochrane LA, Prince M, Clarke K Langerhans' cell histiocytosis in the paediatric population: presentation and treatment of head and neck manifestations. J Otolaryngol. 2003;32:33-37.

5. Copley L, Dormans JP. Benign pediatric bone tumors: evaluation and treatment. Pediatr Clin North Am. 1996;43:949-966.

6. Fletcher CD, Bridge JA, Hogendoorn P, Mertens F, eds. WHO Classification of Tumours of Soft Tissue and Bone. $4^{\text {th }}$ ed. Lyon, France: IARC; 2013.

7. Gafur OA, Copley LA, Hollmig ST, Browne RH, Thornton LA, Crawford SE. The impact of the current epidemiology of pediatric musculoskeletal infection on evaluation and treatment guidelines. J Pediatr Orthop. 2008;28:777-785.

8. Ghanem I, Tolo VT, D'Ambra P, Malogalowkin MH. Langerhans cell histiocytosis of bone in children and adolescents. J Pediatr Orthop. 2003;23:124-130.

9. Heyning FH, Kroon HM, Hogendoorn PC, Taminiau AH, van der Woude HJ. MR imaging characteristics in primary lymphoma of bone with emphasis on non-aggressive appearance. Skeletal Radiol. 2007;36:937-944.

10. Hindman BW, Thomas RD, Young LW, Yu L. Langerhans cell histiocytosis: unusual skeletal manifestations observed in thirtyfour cases. Skeletal Radiol. 1998; 27:177-181.

11. Howarth DM, Gilchrist GS, Mullan BP, Wiseman GA, Edmonson JH, Schomberg PJ. Langerhans cell histiocytosis: diagnosis, natural history, management, and outcome. Cancer. 1999;85:2278-2290.

12. Islinger RB, Kuklo TR, Owens BD, Horan PJ, Choma TJ, Murphey MD, Temple HT. Langerhans' cell histiocytosis in patients older than 21 years. Clin Orthop Relat Res. 2000;379:231-235.

13. Jaffe R, Weiss LM, Facchetti F. Tumours derived from Langerhans cells. In: Swerdlow SH, Campo E, Harris NL, Jaffe ES, Pileri SA, Stein H, Thiele J, Vardiman JW, eds. World Health Organization Classification of Tumours of Haematopoietic and Lymphoid Tissues. Lyon, France: IARC Press; 2008:358.

14. Jawad MU, Schneiderbauer MM, Min ES, Cheung MC, Koniaris LG, Scully SP. Primary lymphoma of bone in adult patients. Cancer. 2010;116:871-879.

15. Lones MA, Perkins SL, Sposto R, Tedeschi N, Kadin ME, Kjeldsberg CR, Wilson JF, Zwick DL, Cairo MS. Non-Hodgkin's lymphoma arising in bone in children and adolescents is associated with an excellent outcome: a Children's Cancer Group report. J Clin Oncol. 2002;20:2293-2301.

16. Mayo-Smith W, Rosenthal DI, Kattapuram SV, Rosenberg AE. Case report 542: eosinophilic granuloma of femur. Skeletal Radiol. 1989;18:245-247.

17. Oliveira M, Steinbok P, Wu J, Heran N, Cochrane D. Spontaneous resolution of calvarial eosinophilic granuloma in children. Pediatr Neurosurg. 2003;38:247-252.

18. Plasschaert F, Craig C, Bell RS, Cole WG, Wunder JS, Alman BA. Eosinophilic granuloma: a different behavior in children than in adults. J Bone Joint Surg Br. 2002;84:870-872.

19. Postini AM, Andreacchio A, Boffano M, Pagano M, Brach Del Prever A, Fagioli F. Langerhans cell histiocytosis of bone in children: a long-term retrospective study. J Pediatr Orthop $B$. 2012;21:457-462.

20. Robinson P, White LM, Sundaram M, Kandel R, Wunder J, McDonald DJ, Janney C, Bell RS. Periosteal chondroid tumors: radiologic evaluation with pathologic correlation. AJR Am J Roentgenol. 2001;177:1183-1188.

21. Wyers MR. Evaluation of pediatric bone lesions. Pediatr Radiol. 2010;40:468-473.

22. Yanagawa T, Watanabe H, Shinozaki T, Ahmed AR, Shirakura $\mathrm{K}$, Takagishi $\mathrm{K}$. The natural history of disappearing bone tumours and tumour-like conditions. Clin Radiol. 2001;56:877-886. 